spent with an armed group, their experiences within that group and the degree and quality of post-conflict support they receive. Wessells (2009) suggests that the majority of former child soldiers exhibit significant resilience, but the extent to which they can successfully be reintegrated into their community of origin strongly influences longer-term adjustment. Thus, there are many potentially exacerbating and mitigating factors that render unwise generalised statements concerning the degree of risk to child soldiers' mental health.

Brandon Kohrt and his colleagues agree that we know little of the needs or efficacy of interventions to support former child soldiers and aid their social integration. They describe lessons learned from their work with the Transcultural Psychosocial Organization in Nepal, where both insurgent Maoist groups and government forces conscripted large numbers of children. Because their intervention was with conflict-exposed children in general, not just with those who had been soldiers, they address some of the questions raised by the Singh review.

Kohrt and colleagues emphasise that, for some children who participated in armed groups, it is the experiences they have after returning home that are the most troubling and liable to provoke a deterioration in mental health. Ways of managing their reintegration, to optimise outcomes, are discussed in a fascinating review by Theresa Betancourt of her work in Sierra Leone, which has followed up former child soldiers for the best part of a decade. She concludes that services should be based on need rather than labels; all three articles concur on that important point.

\section{Reference}

Wessells, M. (2009) Supporting the mental health and psychosocial wellbeing of former child soldiers. Journal of the American Academy of Child and Adolescent Psychiatry, 48, 587-590.

\title{
The mental health consequences of being a child soldier - an international perspective
}

\section{Aoife R. Singh ${ }^{1}$ and Ashok N. Singh ${ }^{2}$}

${ }^{1}$ FY1 doctor in Leicester, UK, email aoifesingh@hotmail.co.uk; ${ }^{2}$ Consultant Psychiatrist, Pilgrim Hospital, Boston, UK

W orldwide there are currently 300000 child soldiers. Not only does the use of child soldiers lead to individual suffering but it also alters the dynamics of war and makes conflict and instability more likely. It is important both to prevent recruitment and to rehabilitate former child soldiers into their communities. For rehabilitation and reintegration programmes to be effective, it is necessary to understand the consequences of child soldiering. This paper reviews and summarises some of the key findings related to the mental health consequences of being a child soldier.

The use of children in fighting forces is not a new phenomenon. Their use was documented in the Old Testament of the Bible - for example David's service to King Saul - as well as in Greek mythology (such as the story of Hercules and Hylas), philosophy and literature. In more recent times, children fought for and against the Nazis in the Second World War. However, in the post-Cold War era, the use of child soldiers has increased dramatically. This increase is linked to various factors, such as the development of lightweight firearms, which can be handled by children as young as 10 years, the metamorphosis of conflict from a predominately inter-state into a predominately long-term, low-intensity intra-state phenomenon, and the undermining of social structures by catastrophes such as HIV/AIDS.

The term 'child soldier' was defined by the United Nations Children's Fund (UNICEF) in the Cape Town Principles as 'any person under 18 years of age who is part of any kind of regular or irregular armed force in any capacity' (UNICEF, 1997), and that definition is followed here.

\section{Method of review}

Various electronic databases were searched, including MEDLINE (1966 to present), EMBASE, CINAHL, IBSS, ALTA, EconLIT and PsycLIT. In addition, the websites of the main organisations involved with child soldier advocacy were searched, for example those of the United Nations, the Coalition to Stop the Recruitment of Child Soldiers, Amnesty International and the United States Agency for International Development (USAID).

\section{Key findings}

The key mental health consequences reported in the literature were related to post-traumatic stress disorder (PTSD), the ability of child soldiers to become normal socialised adults, and alcohol and drug misuse.

\section{Post-traumatic stress disorder}

Derluyn et al (2004) interviewed 301 Ugandan former child soldiers. Of the 71 who completed the self-report Impact of Event Scale for PTSD, 69 (97\%) reported post-traumatic stress reactions of clinical importance. The authors concluded that 
there were no significant differences for boys and girls in PTSD, and that the age of the child, period of abduction, number of traumatic experiences and type of traumatic experiences had little or no effect on PTSD symptoms. Kangaratnam et al (2005) also used the Impact of Event Scale but focused just on the relationship between PTSD and ideological commitment in former child soldiers from Sri Lanka who were now living in Norway. They found that the sample as a whole had been exposed to potentially traumatising events and that 17 (85\%) had a clinically significant score suggesting PTSD.

Much of the remaining literature also found that child soldiers were suffering from post-traumatic symptoms. Boothby et al (2006) studied 39 former child soldiers from Mozambique, who were now adults. All of them experienced recurrent thoughts or memories of their past traumatic experiences. De Silva et al (2001) interviewed 19 former child soldiers in Sri Lanka and found that 18 (95\%) suffered from sad mood, 5 (26\%) from flashbacks, 13 (68\%) from preoccupations, 3 (16\%) from anxiety and 10 (53\%) from fears. Amone-P'Olak (2006) looked at 294 Ugandan adolescents who had been abducted into rebel groups. Some form of mental state associated with their experiences was reported by $94 \%$, predominately hopelessness $(90 \%)$, sensitivity $(65 \%)$ and suspiciousness (64\%).

In contrast, Blattman (2006) compared a group of Ugandan former child soldiers with a control group. He looked at response to abduction as a function of exposure (i.e., the length of abduction and exposure to violence), thereby controlling for the differing experiences of child soldiers. He found that, on average, the former child soldiers were nearly as psychologically healthy as the control group, with only $5 \%$ reporting more than 8 of 19 symptoms of distress. While the average psychological trauma was not large, the youths with the most acute psychological impact were disproportionately those who had been abducted. This suggests that though serious psychological trauma is more common in child soldiers, it is only in a minority. Blattman (2006) suggests that instead of focusing on mean differences between groups, the focus should be on the distribution of psychological trauma.

\section{Effects on adult functioning}

Gomez (2003) concluded that traumatic experiences were more devastating because they occurred in early childhood (and went on to suggest that gang violence had become a huge problem in El Salvador because of former child soldiers). Other writers have similarly expressed the view that exposure to horrific situations during child development will lead to permanently scarred children (e.g. Pearn, 2003) or a 'lost generation' (UNICEF, 1996).

In contrast, Boothby et al (2006) found in their longitudinal study that the majority of their sample had become productive, capable and caring adults. Only a few had continued to engage in violence, or were so disordered that they were unable to take hold of their lives. Blattman (2006) also found that abduction was only weakly associated with aggression and, overall, former child soldiers were not likely to be more aggressive than their non-abducted peers.

\section{Alcohol and drug misuse}

It is commonly reported that child soldiers are given drugs to decrease their fear and increase their prowess in battle (Pearn, 2003). The only study that attempted to quantify drug use was that conducted by the International Labour Organization (ILO, 2003). It found that occasional or regular consumption of drugs, alcohol and cigarettes was higher for child soldiers in the Congo than for children who had never been recruited. It also compared the rates of use of alcohol, cigarettes and drugs before and after recruitment as a child soldier and found they were substantially higher after (ILO, 2003). Clearly, the use of alcohol and drugs at such a young age has implications for both mental and physical health. Alcohol can lead to depression, psychosis and anxiety and drug misuse is associated with paranoid psychosis, change in personality and depression (Gelder et al, 2001).

\section{Methodological weaknesses of the current research}

There are two broad weaknesses of the current literature. First, in many of the studies no control group was used. This means the effect measured cannot necessarily be solely attributed to the experience of being a child soldier. Derluyn et al (2004) revealed that $66 \%$ of the children's fathers were dead and of this group $46 \%$ of the fathers had been killed. The article does not make explicit whether the killing of these fathers was related to the process of the child becoming a soldier. This example highlights that many children may suffer potentially traumatic events simply because they live in a war zone. The other problem with not having a control group is the implicit assumption that the norm for mental health symptoms is zero. This disregards the fact that in any population there will always be a baseline of mental illness.

Secondly, the term 'child soldier' covers a heterogeneous group whose experiences can vary widely. A finding that child soldiers are more prone to psychological trauma may mask potential differences in terms of age, gender and exposure to certain events. Most papers do not disaggregate the data but treat child soldiers as one group, which can mask the more vulnerable and more resilient subsections of this group.

\section{Conclusion}

There are widely varying views and findings on the mental health consequences of being a child soldier. It must be accepted that being a child soldier and the experiences that it entails can have psychological sequalae. This may or may not be labelled PTSD but the important point is that more research is needed to assess those factors which increase the vulnerability of child soldiers to mental health problems, and the best culturally sensitive ways to address this. Although many writers and some studies suggest that child soldiers will be irreparably harmed by their experiences, the evidence for this is weak. It seems that though some former child soldiers may never recover from their experiences, the majority are not a lost cause and can go on to lead fulfilling adult lives.

Nevertheless, the conclusion that some children will suffer from long-term, possibly severe psychological problems means there do need to be services in place for them. The model of care will need to be tailored to the local setting and take into account the local cultural ideas of the causes of illness. It is unlikely that Western-style mental health services will be the answer, in terms of either resources or appropriateness. 


\section{References}

Amone-P'Olak, K. (2006) Mental states of adolescents exposed to war in Uganda: finding appropriate methods of rehabilitation. Torture, 16, 93-107.

Blattman, C. (2006) The Consequences of Child Soldiering. Households in Conflict Network, Working Paper 22. Institute of Development Studies, University of Sussex. Available at http://www.hicn.org/papers/ wp22.pdf (accessed May 2010).

Boothby, N., Crawford, J. \& Halperin, J. (2006) Mozambique child soldier life outcome study: lessons learned in rehabilitation and reintegration efforts. Global Public Health, 1, 87-107.

Derluyn, I., Broekaert, E., Schuyten, G., et al (2004) Post-traumatic stress in former Ugandan child soldiers. Lancet, 363, 861-863.

De Silva, H., Hobbs, C. \& Hanks, H. (2001) Conscription of children in armed conflict - a form of child abuse. A study of 19 former child soldiers. Child Abuse Review, 10, 125-134.

Gelder, M. G., Lopez-lbor, J. J. \& Andreasen, N. (2001) New Oxford Textbook of Psychiatry. Oxford University Press.
Gomez, J. D. (2003) Growing up in guerrilla camps: the long-term impact of being a child soldier in El Salvador's civil war. Ethos, 30, 327-356.

ILO (2003) Wounded Childhood - The Use of Children in Armed Conflict in Central Africa. Internaitonal Labour Organization. Available at http://www.ilo.org/employment/Whatwedo/Publications/lang--en/ docName--WCMS_116566/index.htm (accessed May 2010).

Kangaratnam, P., Raundalen, M. \& Asbjornsen, A. E. (2005) Ideological commitment and posttraumatic stress in former Tamil child soldiers. Scandinavian Journal of Psychology, 46, 511-520.

Pearn, J. (2003) Children and war. Journal of Paediatrics and Child Health, 39, 166-172.

UNICEF (1996) The State of the World's Children. Oxford University Press.

UNICEF (1997) Cape Town Principles and best practice, adopted at the symposium on the prevention of recruitment of children into the armed forces and on demobilisation and social reintegration of child soldiers in Africa, Cape Town, South Africa. Available at http://www. unicef.org/emerg/files/Cape_Town_Principles(1).pdf (accessed May 2010).

\title{
Four principles of mental health research and psychosocial intervention for child soldiers: lessons learned in Nepal
}

\author{
Brandon A. Kohrt, ${ }^{1,2}$ Mark J. D. Jordans ${ }^{2,3}$ and Christopher A. Morley ${ }^{4}$
}

1'Departments of Psychiatry and Anthropology, Emory University School of Medicine, Atlanta, USA, email brandonkohrt@gmail.com; ${ }^{2}$ Transcultural Psychosocial Organization (TPO-Nepal), Kathmandu, Nepal; ${ }^{3}$ Department of Research and Development, HealthNet TPO, Amsterdam, the Netherlands; ${ }^{4}$ Department of Behavioral Sciences and Health Education, Rollins School of Public Health, Emory University, Atlanta, USA

hild soldiers represent a challenging population for mental health and psychosocial support (MHPSS), as we have little evidence regarding their needs or the efficacy of interventions. Despite an increasing breadth of MHPSS interventions for children affected by war, very
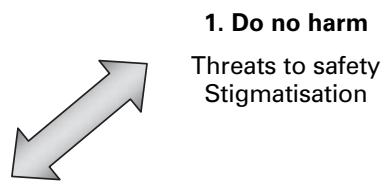

4. Transition from relief to development

Long-term mental health services Multi-layered care network

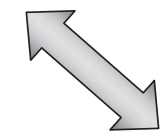

2. Balance research costs and benefits Hierarchies of need Integrated frameworks
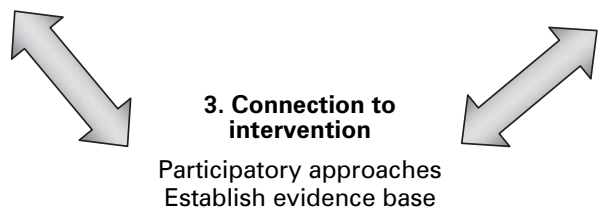

Fig. 1 Child Soldier Four-Principle (C4P) approach to mental health research and psychosocial intervention.

few are supported by evidence (Jordans et al, 2009). In a recent decade-long conflict, Maoists and the government of Nepal conscripted thousands of children to serve as soldiers, sentries, spies, cooks and porters. After the war ended in 2006, we began a project incorporating research into the development of interventions for former child soldiers. Through this work, conducted with Transcultural Psychosocial Organization (TPO) Nepal, we identified four key principles to guide research and intervention with child soldiers (Fig. 1). We present these principles as locationand context-specific examples of the growing effort to develop guidelines and recommendations for research and intervention in acute post-conflict settings (Inter-Agency Standing Committee, 2007; Allden et al, 2009).

\section{Principle 1. Do no harm}

While originating in the clinical ethic of non-maleficence, what is meant by 'do no harm' when working with child soldiers has not been well defined. In conflict settings, harm can manifest as threats to the safety of former child soldiers, their families and their communities. Research and intervention may expose child soldiers who have tried to hide their 